\title{
People's responses to the COVID-19 pandemic during its early stages and factors affecting those responses
}

\author{
Junyi Zhang (iD) ${ }^{1 \times}$
}

The world has suffered from the COVID-19 pandemic. While it is expected that societies will learn lessons from this experience, knowledge about how people responded to the pandemic in its early stages is very limited. With the aim of urgently providing policymakers with scientific evidence about how to better inform the public about fighting against COVID-19, this study made an initial attempt to assess how people responded to the COVID-19 outbreak during its early stages. Based on a life-oriented approach, this study collected data on a large set of behaviors and attitudes through a nationwide retrospective panel survey conducted in Japan at the end of March 2020, when the country had 1953 confirmed infection cases in total. Valid data were collected from 1052 residents from the whole of Japan, taking into account a balanced population distribution in terms of age, gender, and region. Respondents were asked to report changes in their daily activity-travel behavior, long-distance trips, and other life activities caused by the COVID-19 pandemic and associated factors (information reliability, risk perception, attitudes about policy-making and communications with the public, etc.). Results of both aggregate and modeling analyses (using a structural equation model and a data mining approach) indicate that poor communication with the public may have been closely related to the spread of COVID-19 in Japan, and that effective interventions should be made by focusing on interactions between target persons and close members of their social networks. It is also revealed that differentiated communications are necessary to encourage different types of behavioral changes. Risk communication should be better designed to encourage people to voluntarily modify their needs in life $[\mathrm{L}]$ and perform the needed activities [A] at places with sufficient spaces [S] and proper duration of time and at the proper timing [TING]. Such a LASTING approach may be crucial to enhance the effects of massive public involvement in mitigating the spread of COVID-19. The findings from this study are not only useful to tackle the current pandemic, but also have a long-term value for addressing future pandemics.

\footnotetext{
${ }^{1}$ Mobilities and Urban Policy Lab, Graduate School of Advanced Science and Engineering, Graduate School for International Development and Cooperation,

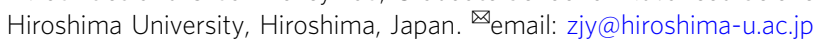




\section{Introduction}

he world is facing multiple challenges due to the COVID19 pandemic, such as lockdowns, restrictions on trip making, and the closure of schools and businesses. The WHO declared that COVID-19 was a pandemic on March 11, 2020 , when more than 125,000 cases and nearly 5000 deaths across the world were identified. Since that time, the number of infections worldwide has increased continuously. As of January 7, 2021 , the total number of cases worldwide stood at $87,343,860$, with total deaths reaching 1,886,348 (https://coronavirus.jhu.edu/ map.html). The United States has suffered most, with 361,312 deaths, followed by Brazil (198,974 deaths), India (150,336 deaths), and Mexico (129,987 deaths). Such a threat to public health is not the first in human history. COVID-19 is often compared with the Spanish Flu or the 1918 flu pandemic. At that time, nobody seemed to know what the disease was, where it came from or how to stop it (Soper, 1919). Other recent examples include the Ebola outbreak in 2019, the Ebola hemorrhagic fever in 2014, the H1N1 influenza virus in 2009, the 2005-2016 Zika fever, and SARS in 2003. However, looking at what's going on across the world, it seems that society has not yet learned the lessons from history and from what happened during the current pandemic.

A critical scientific question is, why could not we stop the rapid spread of the COVID-19 outbreak in its early stages? To answer this question, it is necessary to look back at what happened in the early stages of this pandemic. If everybody had taken appropriate actions against this virus, such as canceling overseas and domestic inter-city trips, teleworking, keeping social distance, wearing masks, washing hands, and so on, the pandemic would probably not have happened. Because of various unknowns about this virus, not only the general public, but even governments and their teams of experts could not respond quickly in the early stages of the pandemic. This should be scientifically investigated as soon as possible so that those countries which are still in the early stages of the pandemic can take immediate measures.

The inconsistent and sometime "inconvenient" practices currently imposed in various countries suggest that historical experiences of public health threats cannot always provide reference points to policymakers. Because this virus is so different from previous ones, the findings from existing studies on other viruses may not be directly applied to the current situation. As cited by Bavel et al. (2020), Soper (1919) pointed out three main factors which stood in the way of prevention during the $1918 \mathrm{flu}$ pandemic: (1) people did not appreciate the risks they run, (2) people could not understand that shutting themselves up in rigid isolation was an effective means of protecting others, and (3) people unconsciously acted as a continuing danger to themselves and others. However, almost every aspect of our society in the $21^{\text {st }}$ century is different from the society of over 100 years ago. Even keeping historical lessons in mind, and drawing on recent evidence about the Ebola outbreak in 2019 (Skrip et al., 2020), the Ebola hemorrhagic fever in 2014 (Sell et al., 2016), the H1N1 influenza virus in 2009 (Pasquini-Descomps et al., 2017), the 2005-2016 Zika fever (Piltch-Loeb et al., 2019), and SARS in 2003 (Yang et al., 2020), West et al. (2020) still argue for an urgent need for behavioral interventions to reduce the transmission of COVID-19. In line with this argument, Cowling et al. (2020) conducted a telephone-based repeated cross-sectional survey on risk perceptions, attitudes, and measures taken against COVID-19 on Jan 20-23, Feb 11-14, and March 10-13, 2020, for about 1000 individuals, respectively. They compared average values of major survey items and concluded that the suppressed spread of COVID-19 in Hong Kong was associated with nonpharmaceutical interventions (e.g., border restrictions, quarantine and isolation, distancing, and behavioral changes). However, relationships across factors, and the size of influence of factors on the suppressed spread, remain unknown due to the lack of proper modeling analyses. Other related studies cannot be found in the literature at the time of writing. To fill the above research gap, this study makes an initial attempt to assess how people in Japan responded to COVID-19 in its early stages, based on a nationwide retrospective panel survey covering a large set of behaviors and psychological factors. The survey and analyses in this study are based on a life-oriented approach (Zhang, 2014, 2017). Based on both aggregate analyses and modeling assessments, this study aims to urgently provide policymakers with immediate scientific evidence about how to better inform individual citizens on how to fight the virus. The study focuses on individual citizens, because they are at the center of collective actions against COVID-19. This study also has a long-term value in that it can help improve our responses to future public health threats.

For the above research purpose, this study implemented the aforementioned online panel survey, at the end of March 2020, when 1953 infected cases were confirmed in Japan and the pandemic was in its early stages. As of May 7, 2020 when the original version of this paper was submitted, the confirmed cases were $15,253^{1}$. With the assistance of a major website survey company, valid data was collected from 1052 residents from the whole of Japan with a balanced population distribution in terms of age, gender and region. ${ }^{2}$ The online survey was implemented on March 23-30, 2020. Respondents were asked to report how their various behaviors changed between January and March, 2020. Major events and measures taken before and during the survey period are summarized below. These events/measures are expected to affect people's behavioral changes.

- January 30: The Japanese government formally established a headquarter for dealing with the novel coronavirus [Global deaths: 213].

- January 31: WHO announced that the novel coronavirus is a Public Health Emergency of International Concern [Global deaths: 259].

- February 1: The first infection case was confirmed on the Diamond Princess cruise ship [Global deaths: 304].

- February 11: WHO formally named the virus as COVID-19 [Global deaths: 1115].

- February 13: The first death in Japan was confirmed [Global deaths: 1383].

- February 25: A task force of cluster countermeasures was formally established by the Japanese government. This was also the start of the so-called Japan-specific countermeasures. Concretely speaking, instead of making a thorough check of the population, the Japanese government started to identify and target clusters of infection [Global deaths: 2763].

- February 28: The first declaration of a state of emergency. ${ }^{3}$ in Japan was made by the governor of Hokkaido Prefecture [Global deaths: 2923].

- March 2: All elementary, secondary and high schools in Japan temporarily suspended until the spring break (April 6) [Global deaths: 3117].

- March 11: WHO announced that the COVID-19 outbreak is a pandemic [Global deaths: 4627; Total infection: 126,215].

- March 19: Recommendations of behavioral changes by a governmental task force were released in Japan [Global deaths: 10,077].

- March 25: The Tokyo governor announced her requests for self-restraint on weekends [Global deaths: 21,746].

- March 30: The Tokyo governor further announced her requests for self-restraint on both weekends and weekdays [Global deaths: 39,334]. 
In the remaining sections, the design and implementation of the questionnaire survey are first described, and then aggregate and modeling analyses are conducted. Aggregate analyses are divided into two parts: (1) changes in life, and (2) factors associated with these changes. After these analyses, two modeling analyses are further implemented: one is based on a structural equation model (SEM) with latent variables, and the other is based on a data mining approach. Finally, the findings are discussed, and the study concludes with future policy and research recommendations.

\section{Design and implementation of questionnaire survey}

Because of the COVID-19 outbreak, various changes in daily routines and activities have been imposed on almost all aspects of our society. As a result, people have had to adapt to these impacts, for example by cancelling some activities in response to requests or regulations from governments, and/or modifying other activities to keep social distance based on voluntary will. Mass surveys, such as those conducted by Statista.com and Google, have investigated various aspects of changes in life due to the COVID19 outbreak. ${ }^{4}$ However, the survey items about changes are not comprehensive, and consequently cannot capture the full picture of changes in life at an individual level. Furthermore, the factors behind these changes have not been explored.

To overcome the shortcomings of existing surveys and studies, a retrospective panel survey was designed based on the lifeoriented approach (Zhang, 2014, 2017), which captures various life activities and decisions in terms of life domains, and emphasizes behavioral interdependencies. In other words, a change in a certain behavior may induce or directly lead to changes in other behaviors. Retrospective panel surveys, which ask respondents to recall what happened in the past, have been widely applied in different research fields (e.g., Caputo et al. 1992; Belli, 1998; Schröder, 2011; Thigpen, 2019).

Detailed survey items are summarized in Table 1 . In addition to those listed, individual and household attributes are also included. In the survey, behavioral changes were investigated together with the timing (dates) of changes. Time use for different activities on weekdays and weekends undertaken during the period December 2019 to February 2020 and March 2020 were compared. The period December 2019 to February 2020 was chosen because before the Japanese government made the first announcement of school closures on February 28, Japanese people had not had any serious perceptions about this virus, in the sense that everything was "business as usual". The following categories are included in the survey as potential factors associated with behavioral changes: direct triggers of behavioral changes, reliability of COVID-19-related information, risk perceptions about the COVID-19 infection, attitudes about policymaking and personal willingness, and individual and household attributes. Introducing the trigger questions is straightforward. Reliable information allows people to make firm decisions on behavioral changes. The higher the infection risk perceived by a person, the more likely the person will change his/her behaviors against the risk. Whether and how to follow governmental instructions depend not only on how people evaluate governments and their policymaking, but also on people's willingness to cooperate with governments; these are captured by attitudinal questions. A public opinion survey on the use of nuclear energy designed by the Japan Atomic Energy Relations Organization in $2015^{5}$ provided hints for some of the attitudinal questions in this survey.

Ethics statement. This study was approved by the ethics committee of the author's university (Approval Number: HUIDEC-
2020-0009), confirming that informed consent was obtained from all participants.

Data collection and sample characteristics. Table 2 shows the distributions of gender, age, and region for the 1052 respondents, which were controlled to be almost the same as those of the whole population in Japan. The sample size was determined by the available budget. Among the respondents, $45.0 \%$ had a university degree or above. As for the respondents' occupations, $41.2 \%$ were in the private sector, $6.2 \%$ were in the public sector and schools and education organizations, $15.9 \%$ were housewives or househusbands, $13.8 \%$ were part-time employees, $9.2 \%$ were students, and $10.6 \%$ did not have a job (including pensioners). Married respondents accounted for $50.9 \%$ and single people were $42.5 \%$. The average number of household members living together was 2.56 persons: $49.0 \%$ were couples, while 29.3 and $29.1 \%$ were living together with children and parents, respectively. The percentage of respondents living in their own houses was $44.3 \%$. Lastly, concerning annual household income levels, $24.1 \%$ had less than 3 million Yen (approximately US\$28,800), 27.8\% between 3 million and 5 million Yen (approximately US $\$ 28,800$-US\$48,000), 26.8\% between 5 million and 8 million Yen (approximately US\$48,000-US\$76,840), and 21.2\% had more than 8 million Yen. ${ }^{6}$

\section{Changes in life}

Examples of daily life changes can be found in the survey links given in Footnote 4. For other non-daily activities, tourism may be more vulnerable to the COVID-19 pandemic than other activities. On March 27, 2020, the World Travel and Tourism Council published a short report on the impacts of the pandemic on global tourism. It estimated that globally, up to 75 million jobs were at immediate risk, especially in the Asia-Pacific region (up to 49 million jobs), and that global loss of travel and tourism GDP would reach $\$ 2.1$ trillion in 2020 . $^{7}$ In Japan, about $70 \%$ of travel bookings were cancelled in March and April 2020, ${ }^{8}$ while a major Shinkansen company (Tokaido) reported a 59\% reduction of ridership in March $2020 .^{9}$

Changes in bookings. Serious impacts of the spread of COVID19 on the economy were observed from our survey (Fig. 1). By the end of March 2020, activities which saw booking cancellation rates higher than $50 \%$ due to the COVID-19 outbreak were scheduled music concerts ( $16 \%$ of respondents had bookings, of which $58 \%$ were cancelled), overseas tourism trips ( $9 \%$ had bookings, of which $58 \%$ were cancelled), watching sports $(13 \%$ had bookings, of which $57 \%$ were cancelled), overseas business trips ( $5 \%$ had bookings, of which $54 \%$ were cancelled), domestic business trips ( $12 \%$ had bookings, of which $54 \%$ were cancelled), and gatherings ( $38 \%$ had bookings, of which $53 \%$ were cancelled). Other higher cancellations were domestic flight (10\% had bookings, of which $49 \%$ were cancelled), domestic tourism trips ( $25 \%$ had bookings, of which $42 \%$ were cancelled), and watching movies (22\% had bookings, of which $40 \%$ were cancelled).

As the temporal changes in rates of both cancellations and postponements shown in Fig. 2 reveal, soon after February 28 when the central government announced the closure of schools for the whole country, the rates of cancellations/postponements showed a big jump on March 1 and kept growing after then. The fastest type of activities which saw cancellations/postponements was overseas tourism trips ( +16 points), followed by domestic business trips ( +15 points). Overseas business trips and watching sports were ranked as the third and fourth positions in terms of rates, suggesting a delayed response for several more days 


\section{Table 1 Major survey items.}

\section{Changes in life}

Change in booking: cancellation or postponement or no change, and the timing (date) of change, in the case of change

$\checkmark$ Trips

- Domestic tourism trips

- Domestic business trips

- Overseas tourism trips

- Overseas business trips

- Domestic flights

- Domestic intercity railway

- Other domestic inter-city travel modes

$\checkmark$ Activities

- Music concerts

- Watching sports

- Watching movies

- Eating out

- Gatherings (e.g., party)

Changes in daily life and the timing (date) of change (yes or no) $\checkmark$ Work/school-related

- Time to go to work and leave work became more flexible

- More commuting/schooling trips were made during offpeak hours

- Stop-by behavior during commuting or schooling declined

- Telework and study at home increased

- The amount of work decreased

$\checkmark$ Shopping

- Online shopping and tele-shopping increased

- Shopping at stores decreased

- Online and telephone orders for meals increased

$\checkmark$ Family life

- There were more conversations with family

- Personal time for housework increased

- Family members' time for housework increased

- Eating out decreased

$\checkmark$ Travel behaviors:

- Daily

$\square$ Daily trips decreased

$\square$ Use of public transport decreased

$\square$ Travel by car increased

$\square$ Walking and cycling increased

- Non-daily

$\square$ Domestic travel decreased

$\square$ Overseas travel decreased

$\checkmark$ Sports, recreation

- More time was spent on hobbies

- Exercise frequency and time increased

- Exercise frequency and time decreased

$\checkmark$ Social networking

- SNS at home increased

- Face-to-face communications with friends and acquaintances decreased

- Visiting crowded places was avoided as much as possible

$\checkmark$ Sleep time increased
Factors and consequences

Triggers of changes in life

$\checkmark$ Triggered by personal understanding about the COVID-19 situations

$\checkmark$ Triggered by requests from governments

$\checkmark$ Triggered by requests from workplace/school

$\checkmark$ Triggered by recommendations from family

$\checkmark$ Triggered by recommendations from colleagues, acquaintances and friends

Factors associated with the above changes and cancellations

$\checkmark$ Knowledge about COVID-19

- Four items: "yes or no" questions

$\checkmark$ Searching/accessing time (minutes per day) about COVID-19 information by type of source

-TV, SNS, radio, face-to-face communication, paper-based media

$\checkmark$ Reliability of COVID-19 information by source (5-point Likert scale)

- Central government, municipalities, experts, domestic news, oversea news, medical institutes, workplace and school

$\checkmark$ Perceptions about infection risks (5-point Likert scale)

- Personal perceptions about risks at nation, residence prefecture, residence city/ town, residence community

- Perceptions about how other persons surrounding respondents perceive risks at nation, residence prefecture, residence city/town, residence community

$\checkmark$ Perceptions about the dangerousness of COVID-19 and personal infection risk

(5-point Likert scale)

$\checkmark$ Attitude items (5-point Likert scale)

- Information disclosure

$\square$ Public disclosure of information about the actual status of infection by the Japanese government is sufficient

$\square$ Information on the actual state of the infection is sufficiently disclosed by the local government of the area where you live

- Expertise

$\square$ Japanese health and medical institutions have sufficient expertise

$\square$ The Japanese government has sufficient expertise

$\square$ The local government of the area where you live has sufficient expertise

- Fair view

$\square$ The Japanese government has a fair view of the COVID-19 infection

$\square$ The municipalities you live in have a fair view of the COVID-19 infection

- Enthusiasm

$\square$ You can feel the Japanese government's enthusiasm in preventing the spread of infection

$\square$ You can feel the enthusiasm of the local government of the area where you live in preventing the spread of the infection

- Readiness

$\square$ To prevent the spread of infection, the management system and measures of the Japanese government are in place

$\square$ To prevent the spread of infection, the management system and measures of the local government of the area where you live are in place

- Trust

$\square$ You can trust the Japanese health and medical bodies in preventing the spread of infection

$\square$ You can trust the Japanese government in preventing the spread of infection

$\square$ You can trust the local government of the area where you live in preventing the spread of infection

- Accountability

$\square$ The Japanese government should be more accountable

$\square$ The local government where you live should be more accountable

- Policy intensity

$\square$ The Japanese government should take nationwide measures more thoroughly

$\square$ The local government where you live should take related measures more thoroughly

$\square$ Local governments where infection has not been confirmed do not need to take related measures at this moment

- Use of privacy information 


\section{Table 1 (continued)}

Changes in life
- Expenditures
- Household energy consumption increased
- Household energy consumption decreased
- Tried to reduce the whole household expenditure as much as
possible
- Medical expenses increased
$\checkmark$ Panic buying
- Tried to purchase as many masks as possible
- Tried to purchase antiseptic solution as much as possible
- Tried to purchase emergency food as much as possible
- Tried to purchase daily necessities as many as possible
$\checkmark$ Time use (minutes) on weekdays and weekends: before
(December 2019 to
$\checkmark$ February 2020 ) and after the COVID-19 pandemic (March
2020 ) in Japan
- In-home: sleeping, housework, work/study, discretionary time
- Out-of-home: trip making, work/study, discretionary time, other
private matters
Changes in health and values
$\checkmark$ Became tired mentally and physically after longer stay at home
$\checkmark$ Tried to encourage other people's behavioral changes against
the infection
$\checkmark$ Whether the view of life changed due to COVID-19 or not

Factors and consequences

$\square$ If you become infected, you do not have any psychological resistance to publishing your activity trajectories on an online map

- Responses to governments

$\square$ Looking at the government's current responses, if the COVID-19 is widespread in Japan, you are very worried about it

$\square$ The government's current outbreak control measures have a significant effect on reducing the risk of infection throughout Japan

$\square$ Government's current control measures are likely to cause a short-term stagnation in the Japanese economy

- Willingness

$\square$ Try to self-restrain until the government lifts the self-restraint request

$\square$ Want to be vaccinated if a new coronavirus vaccine is made in the future

$\square$ Worry about infection even after being vaccinated

- General view of life: In general, you live for today and don't think of tomorrow

\begin{tabular}{|c|c|c|c|c|c|c|c|}
\hline \multirow[t]{2}{*}{ Gender } & \multirow[t]{2}{*}{$\begin{array}{l}\text { Age } \\
\text { (years old) }\end{array}$} & \multicolumn{2}{|c|}{$\begin{array}{l}\text { Megacity } \\
\text { regions }\end{array}$} & \multicolumn{2}{|c|}{$\begin{array}{l}\text { Local hub- } \\
\text { cities }\end{array}$} & \multicolumn{2}{|c|}{ Other cities } \\
\hline & & Persons & $\%$ & Persons & $\%$ & Persons & $\%$ \\
\hline \multirow[t]{6}{*}{ Males } & $15-19$ & 15 & 1.4 & 11 & 1.0 & 13 & 1.2 \\
\hline & $20-29$ & 37 & 3.5 & 26 & 2.5 & 22 & 2.1 \\
\hline & $30-39$ & 44 & 4.2 & 29 & 2.8 & 29 & 2.8 \\
\hline & $40-49$ & 48 & 4.6 & 31 & 2.9 & 33 & 3.1 \\
\hline & $50-59$ & 38 & 3.6 & 26 & 2.5 & 32 & 3.0 \\
\hline & $60-69$ & 35 & 3.3 & 30 & 2.9 & 33 & 3.1 \\
\hline \multirow[t]{6}{*}{ Females } & $15-19$ & 11 & 1.0 & 10 & 1.0 & 12 & 1.1 \\
\hline & $20-29$ & 33 & 3.1 & 27 & 2.6 & 23 & 2.2 \\
\hline & $30-39$ & 45 & 4.3 & 31 & 2.9 & 28 & 2.7 \\
\hline & $40-49$ & 44 & 4.2 & 33 & 3.1 & 32 & 3.0 \\
\hline & $50-59$ & 32 & 3.0 & 30 & 2.9 & 27 & 2.6 \\
\hline & $60-69$ & 35 & 3.3 & 33 & 3.1 & 34 & 3.2 \\
\hline
\end{tabular}

compared to the above two types of activities. However, cancellations/postponements of watching sports increased faster than other bookings and eventually reached the largest share of $94 \%$ at the end of March, followed by music concerts (88\%), overseas business trips (87\%), gatherings $(85 \%)$, overseas tourism trips (85\%), domestic business trips (79\%), and watching movies (76\%). Cancellations/postponements of domestic tourism trips and domestic flights increased slowly since the end of the first week of March. Over the whole survey period, domestic intercity railway and other non-flight modes, as well as eating out were cancelled or postponed at a much slower pace than other bookings. Since March 20, the increase in cancellations/ postponements of most bookings almost stopped.

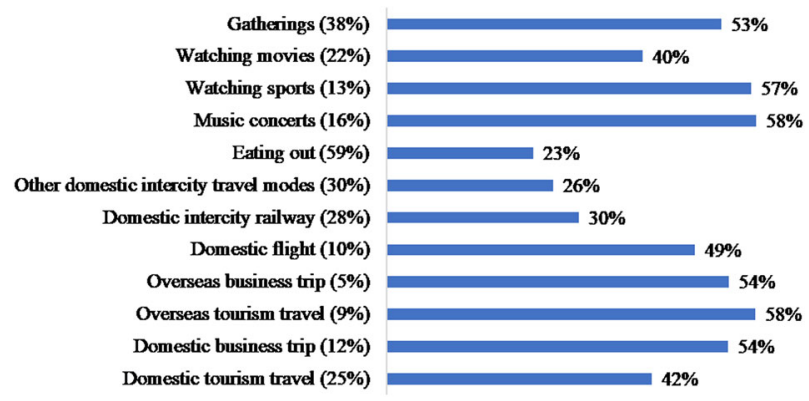

Fig. 1 Cancellation rates due to COVID-19 between January and March 2020. It shows cancellation rates of 12 types of bookings caused by the COVID-19 pandemic in Japan between January and March 2020.

Changes in daily life. As shown in Fig. 3, 75\% of respondents avoided visiting crowded places as much as possible, which is the biggest change observed in the survey. This is followed by $60 \%$ of respondents who reduced daily trips, 53\% reduced eating out, $47 \%$ reduced face-to-face communications with friends and acquaintances, and $40 \%$ reduced shopping at stores. These four changes also showed the biggest changes from February 29 to March 1. Note that March 2 was the start of school closures announced by the central government on February 28.

Changes in travel behavior. The most serious change was the decline in the use of public transport (36\%). As a result, $29 \%$ of respondents increased car trips and $27 \%$ increased walking and cycling. For the scheduling of commuting/schooling trips, only $14 \%$ of respondents made more trips during off-peak hours and $18 \%$ reported that the time to go to work and leave work became more flexible. As for non-daily trips, $27 \%$ of respondents reduced domestic travel and 12\% reduced overseas travel. 


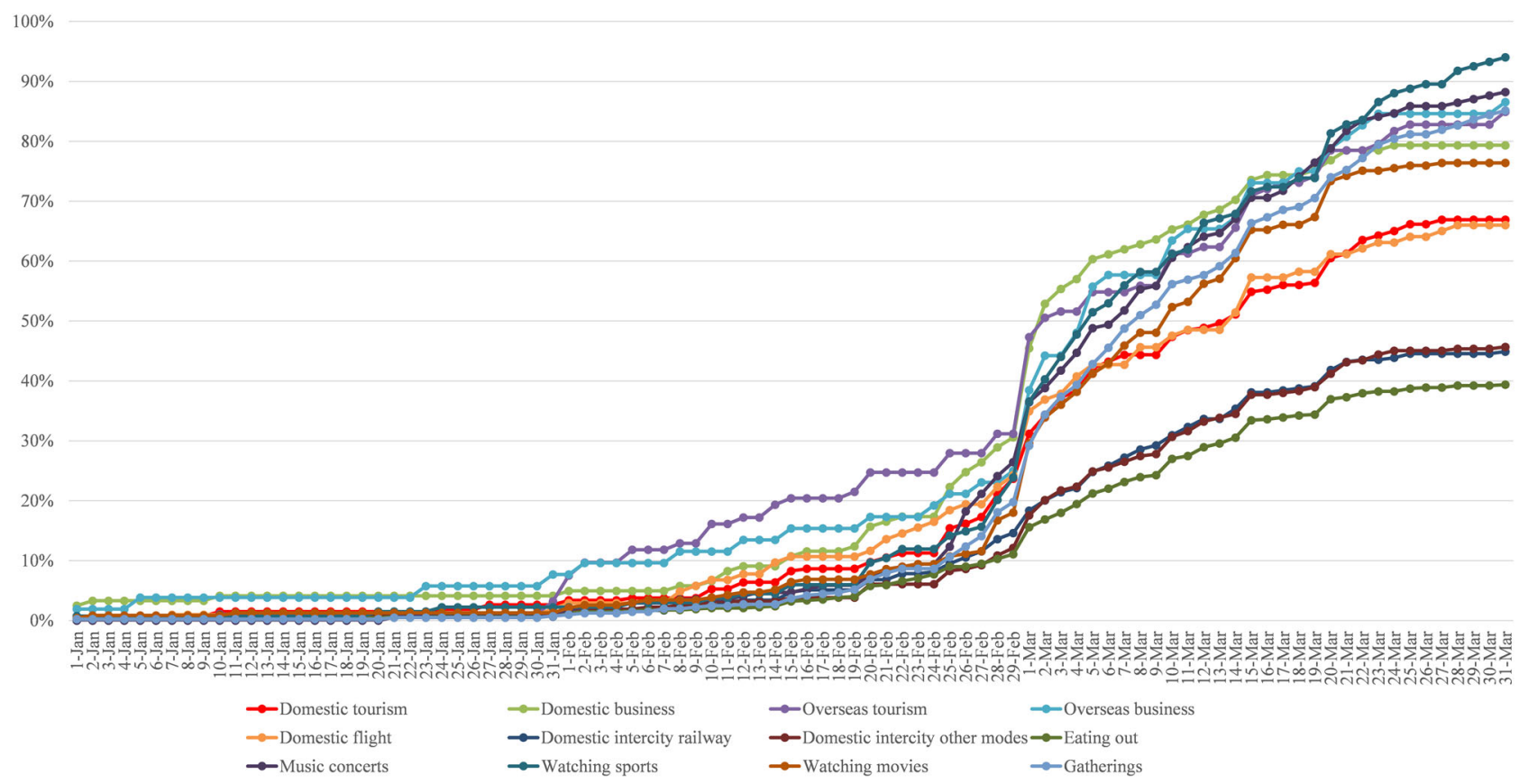

Fig. 2 Temporal transitions of cancellations/postponements due to COVID-19 between January and March 2020. It shows how both cancellation and postponement rates of 12 types of bookings, caused by the COVID-19 pandemic in Japan, change over time between January and March 2020.

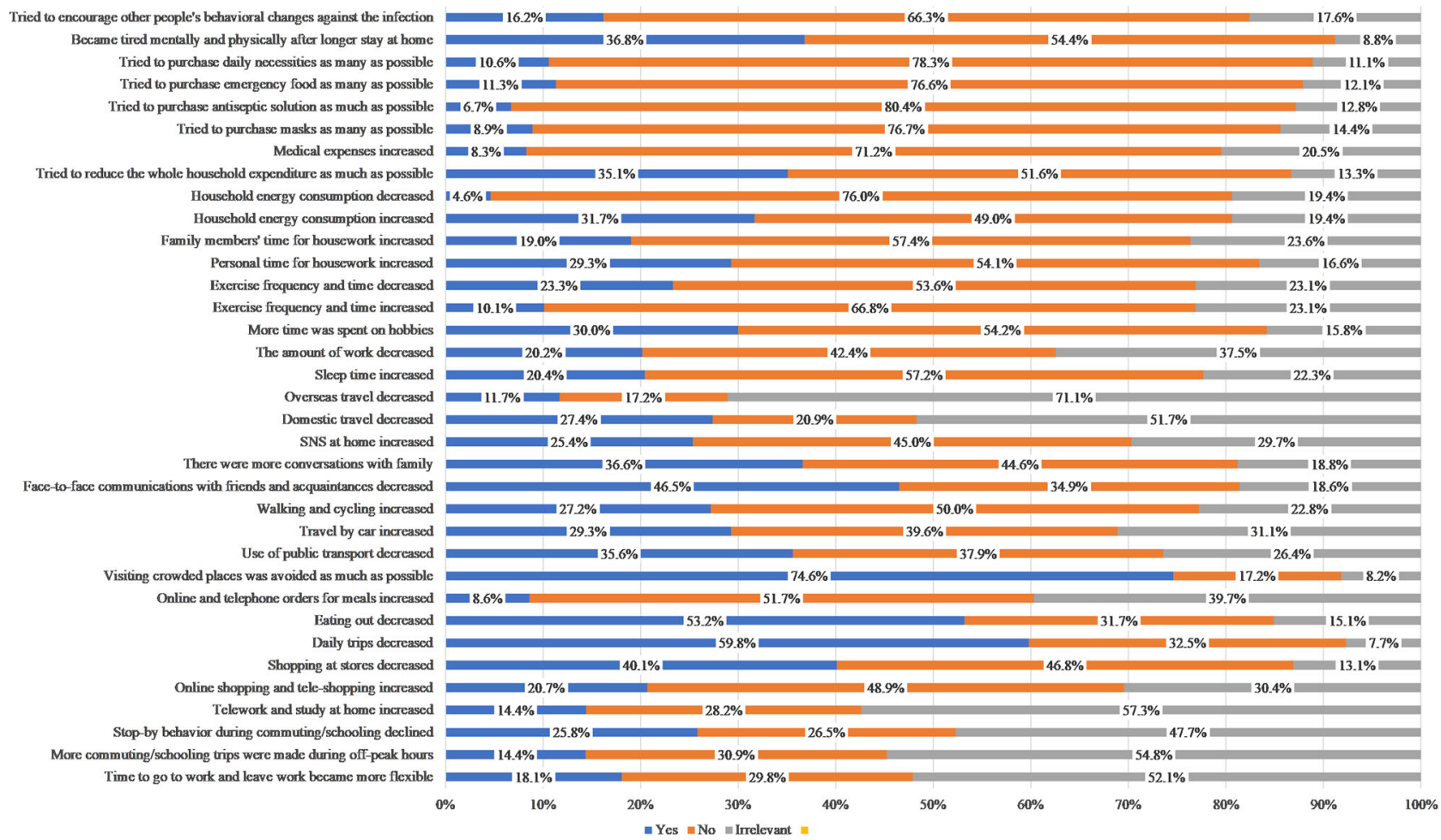

Fig. 3 Changes in Japanese people's daily life before and after the COVID-19 outbreak. It shows whether 35 types of daily life activities changed or not, caused by the COVID-19 pandemic in Japan between January and March 2020.

Changes in activity participation. As expected, there were more changes in time use. There were more conversations with family, as reported by $37 \%$ of the respondents, which was the biggest change in activity participation. People spent more time on hobbies (30\% of respondents), housework (29\%), SNS at home (25\%), sleeping time (20\%), and physical exercise (time and frequency) $(10 \%)$. Increase in telework and study at home was reported by $14 \%$, while increases were also found in online shopping and tele-shopping (21\%) and online/telephone orders for meals $(9 \%)$. Because there were staying-at-home activities, $19 \%$ of respondents reported that their family members increased housework and $23 \%$ said that they reduced the time and 
frequency of physical exercise. With regard to work activities, $20 \%$ answered that the amount of work decreased and $26 \%$ reduced stop-by behaviors during commuting/schooling (stopping somewhere on the way to or from their place of education or work).

Other changes. As consequences of the above changes in activity participation, $32 \%$ of the respondents found that their household energy consumption increased, but 5\% reported a decrease. Meanwhile, 35\% tried to reduce their household expenditure as much as possible, while only $8 \%$ reported an increase in medical expenses.

Because of worries about the infection, $9 \%$ of respondents tried to purchase masks and 7\% tried to purchase antiseptic solution as much as possible. Linked to the above concerns, $11 \%$ of respondents tried to purchase emergency food and daily necessities as much as possible.

To tackle such a serious public health threat, people may have more interactions with each other. It is revealed that $16 \%$ tried to encourage other people's behavioral changes against the infection.

Because of longer stays at home, $37 \%$ of the respondents felt tired, mentally and physically. Finally, respondents were asked about whether the current COVID-19 pandemic would change their views of life or not. About $18 \%$ answered "fully agree" or "agree", and about $41 \%$ answered "fully disagree" or "disagree".

Temporal transitions. Looking at Fig. 4, it is obvious that there were big jumps on March 1 in terms of changes in all areas of daily life. "Visiting crowded places was avoided as much as possible" showed the fastest increase (75\%), followed by "Daily trips decreased" (60\%), "Eating out decreased" (53\%), and "Faceto-face communications with friends and acquaintances decreased" (46\%). What was most remarkable was that "Became tired mentally and physically after longer stay at home" grew at the fastest speed since the middle of March. This should be regarded as one of the biggest health concerns if the pandemic lasts for a longer period than expected. Apart from the above features, several co-growth groups were found.

- $31-40 \%$ of respondents made the following changes: "Shopping at stores decreased" (40\%), "There were more conversations with family" (37\%), "Use of public transport decreased" (36\%), "Tried to reduce the whole household expenditure as much as possible" (35\%), and "Household energy consumption increased" (32\%).

- $21-30 \%$ of respondents made the following changes: "More time was spent on hobbies" (30\%), "Travel by car increased" (29\%), "Personal time for housework increased" (29\%), "Domestic travel decreased" (27\%", "Walking and cycling increased" (27\%), "Stop-by behavior during commuting/ schooling declined" (26\%), "SNS at home increased" (25\%), "Exercise frequency and time decreased" (23\%), and "Online shopping and tele-shopping increased" (21\%).

- $11-20 \%$ of respondents made the following changes: "Sleep time increased" (20\%), "The amount of work decreased" (20\%), "Family members' time for housework increased" (19\%), "Time to go to work and leave work became more flexible" (18\%), "Tried to encourage other people's behavioral changes against the infection" (16\%), "Telework and study at home increased" (14\%), "More commuting/schooling trips were made during off-peak hours" (14\%), "Overseas travel decreased" (12\%), "Tried to purchase emergency food as many as possible" (11\%), and "Tried to purchase daily necessities as many as possible" (11\%).

- The least changing groups: "Exercise frequency and time increased" (10\%), panic buying ("Tried to purchase masks as many as possible" (9\%) and "Tried to purchase antiseptic solution as much as possible" (7\%)), "Online and telephone orders for meals increased" (9\%), "Medical expenses increased" (8\%), and "Household energy consumption decreased" (5\%).

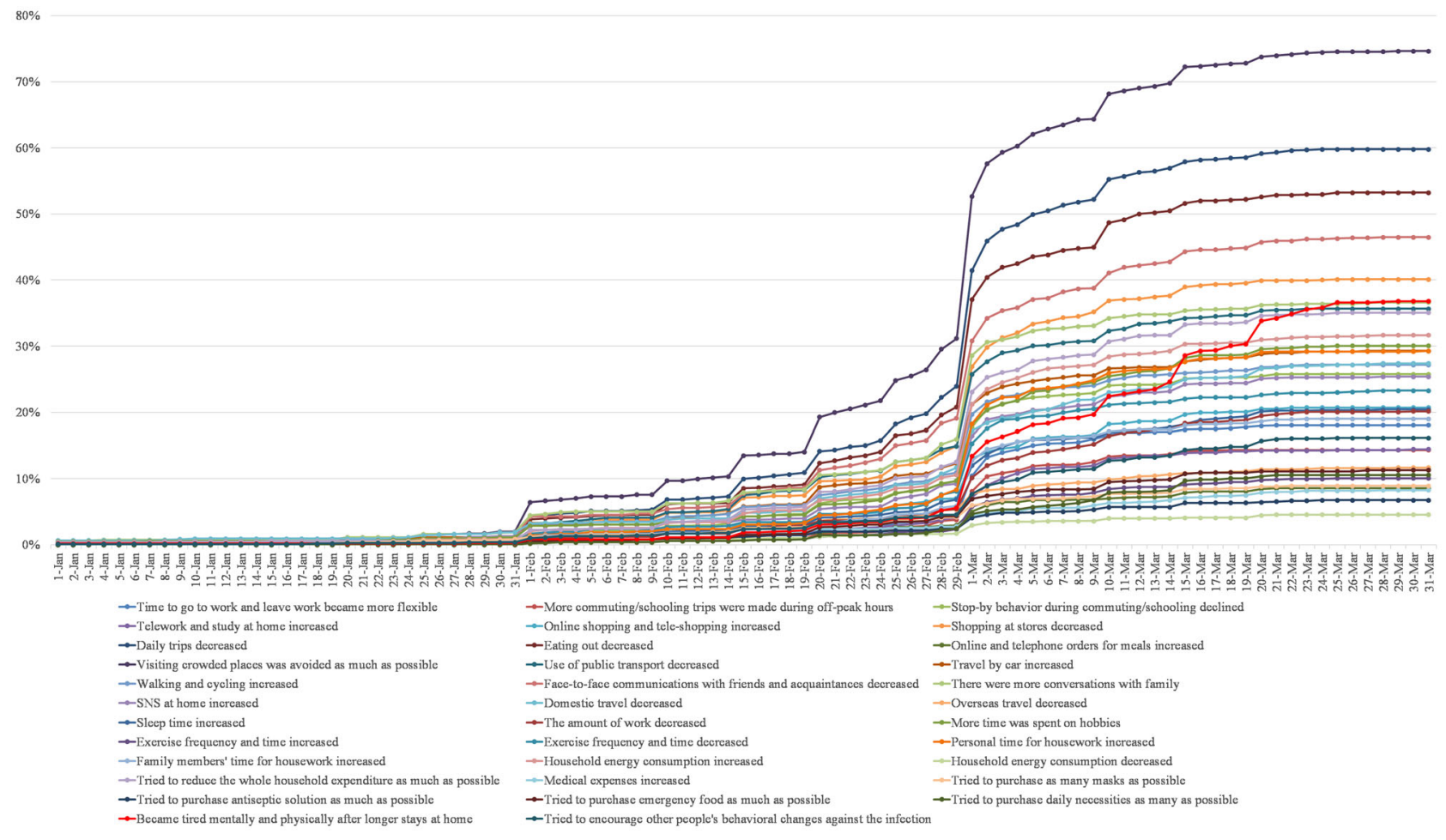

Fig. 4 Temporal transitions of changes in Japanese people's daily life before and after the COVID-19 outbreak. It shows how 35 types of daily life activities caused by the COVID-19 pandemic in Japan change over time between January and March 2020. 
Table 3 Ttriggers causing changes in life.

\begin{tabular}{|c|c|c|c|c|c|}
\hline Triggers & Fully disagree & Disagree & Neutral & Agree & Fully agree \\
\hline Self-understanding & $11 \%$ & $18 \%$ & $32 \%$ & $31 \%$ & $9 \%$ \\
\hline Requests from governments & $10 \%$ & $16 \%$ & $28 \%$ & $33 \%$ & $14 \%$ \\
\hline Requests from workplace/school & $18 \%$ & $19 \%$ & $31 \%$ & $24 \%$ & $9 \%$ \\
\hline Recommendations from colleagues, acquaintance and friends & $18 \%$ & $25 \%$ & $37 \%$ & $17 \%$ & $3 \%$ \\
\hline
\end{tabular}

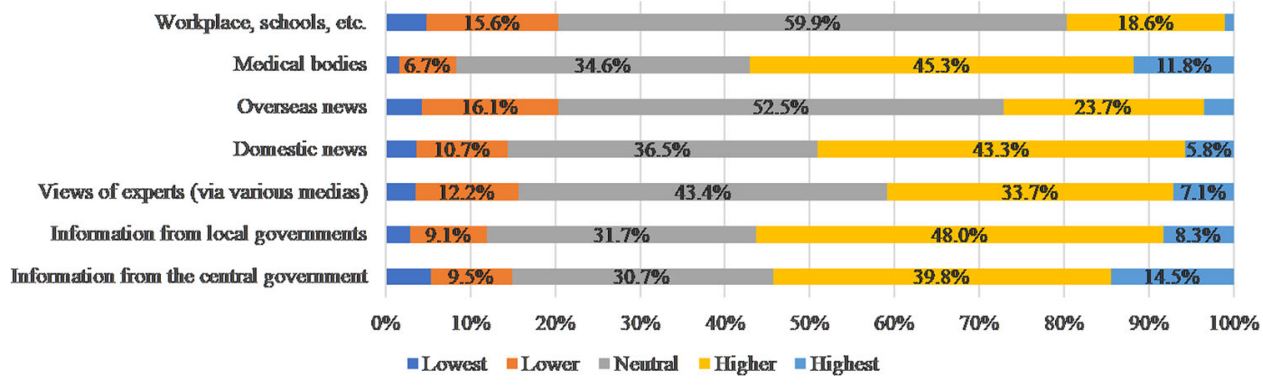

Fig. 5 Evaluation of reliability of COVID-19 information. It shows how the survey respondents evaluated the reliability of 7 types of COVID-19 information sources.

The above-observed co-occurrences of behavioral changes are theoretically supported by the life-oriented approach (Zhang, 2017).

\section{Factors with possible relevance to changes in life}

Triggers of changes. The most reported trigger was requests made by governments ("fully agree" and "agree": $47 \%$; "fully disagree" and "disagree": $25 \%$ ), followed by respondents' personal understanding about the current COVID-19 situations ("fully agree" and "agree": 39\%; "fully disagree" and "disagree": 29\%). For other triggers, the percentages of "fully disagree" and "disagree" were larger than those of "fully agree" and "agree". Detailed results are given in Table 3.

How much are people informed about and interested in COVID-19? In the questionnaire survey, 1052 respondents were asked about their knowledge about COVID-19, in terms of four widely-reported items. Almost all the respondents had knowledge about the virus: $98 \%$ knew that COVID-19 is transmitted from person to person through droplets and contact; $97 \%$ knew that it is necessary to wash hands with soap or antiseptic solution; $93 \%$ knew the symptoms of suspected infections (e.g., cold symptoms or a fever of $37.5^{\circ} \mathrm{C}$ or over for four days or more, but two days for senior citizens or people with underlying health conditions, fatigue or difficulty in breathing). But the percentage knowing the fact "antiseptic solution (with 70\% of alcohol) can kill COVID19 " was $80 \%$. About $97 \%$ knew about the government's announcement on February 28, 2020 that "all elementary, secondary and high schools nationwide must take temporary closure from March 2 until the spring break". Thus, most people show a high interest in this new virus.

The respondents were asked to report how much time, at maximum, they spent every day within the last one week from the day of reporting. It is observed that the respondents received information about the spread of COVID-19 mainly through TV and social media: spending up to $64 \mathrm{~min}$ for TV and $22 \mathrm{~min}$ for social media each day, respectively. Surprisingly, TV is still the most popular mass media in Japan. Even though people were advised to keep social distance, the respondents spent up to $15 \mathrm{~min}$ on face-to-face information exchange with surrounding people (acquaintances, colleagues, etc.). Maximal time spent on radio and paper-based media was less than $10 \mathrm{~min}$.

As for the reliability of various information sources (Fig. 5), health and medical bodies were perceived to be reliable by $57.1 \%$ of the respondents, followed by the information released by local governments (56.3\%). Meanwhile, $54.3 \%$ perceived the information released by the central government to be reliable. The least reliable information was that coming from workplaces and schools.

How much do people perceive the infection risks from COVID-19? As shown in Fig. 6, 79\% of respondents thought that the risk of infection in the whole of Japan was increasing. The corresponding percentages of perceived risk for the residence province, city/town, places visited often, and residence community were $61,48,43$, and $33 \%$, respectively. Even though $58 \%$ thought the virus was dangerous, only $32 \%$ thought they were more likely to be infected than other persons. Very consistently, more respondents thought that other persons surrounding them did not have risk perceptions similar to their own, in terms of the risk levels in the whole country, their residence provinces, cities/ towns, and communities.

Trust in governments and other organizations. As shown in Fig. 7, the respondents agreeing to the statement "the central government and the respondents' residential municipalities had enough knowledge to prevent the spread of COVID-19" were only 18 and $15 \%$, respectively. Only $27 \%$ agreed that Japanese health and medical organizations had sufficient expertise. About $20 \%$ of respondents thought the central government and the residence municipality had a fair view about the COVID-19 infection. More respondents (28\%) felt that the central government had higher enthusiasm in preventing the spread of infection than the respondents' residence municipalities (22\%). About 25\% of respondents thought that public disclosure of information about the actual status of infection by both the central government and residence municipalities was enough. Only about $20 \%$ thought that the management systems and measures of both the central government and residence municipalities were in place. Probably affected by such attitudes, only $24 \%$ of respondents 


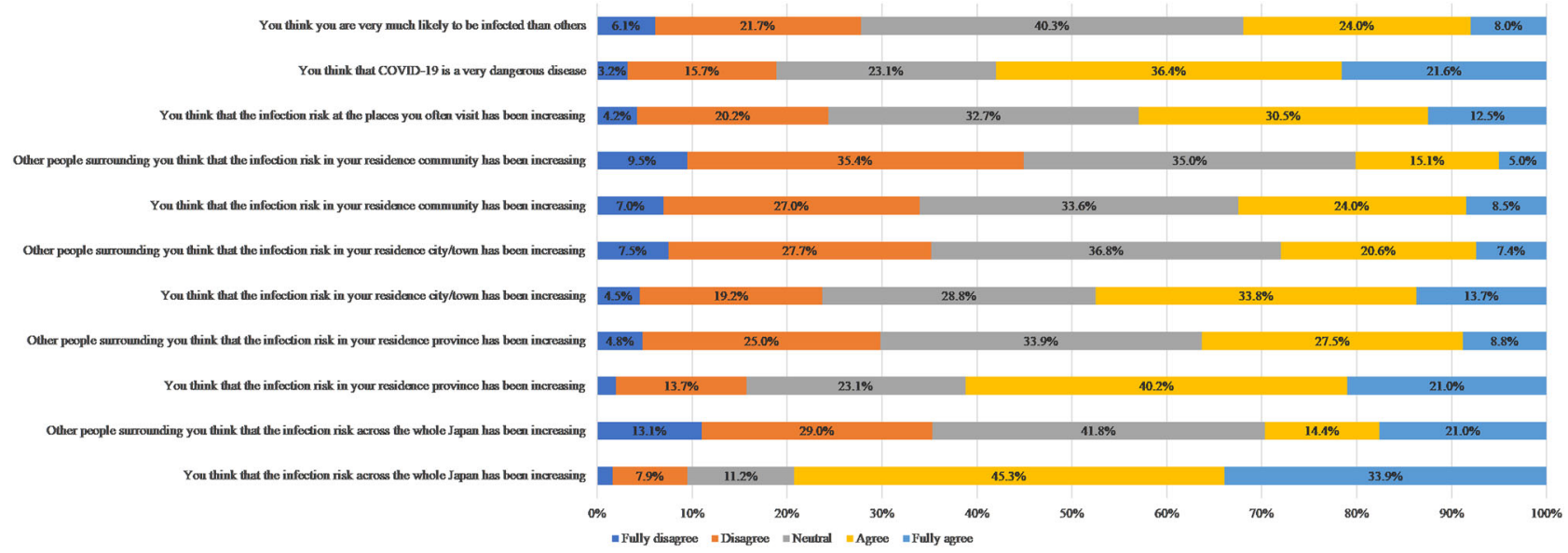

Fig. 6 Perceived infection risks of COVID-19. It shows how the survey respondents perceived infection risks of COVID-19 in terms of 11 aspects.

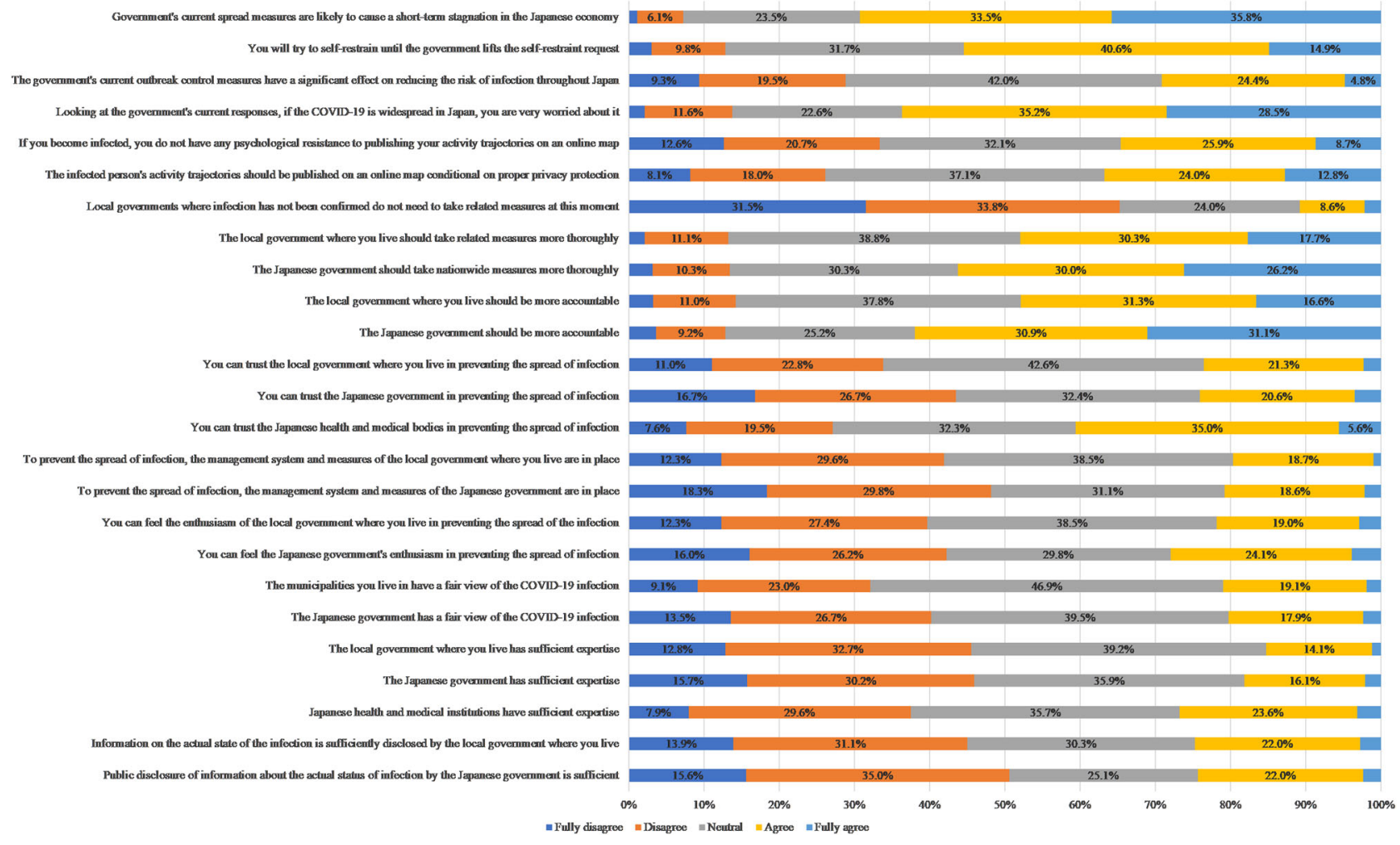

Fig. 7 Psychological attributes of the survey respondents. It shows the survey respondents' 25 psychological attributes, including attitudes about policymaking (e.g., knowledge, trust, accountability, fair views, policy effects and influences,) and personal willingness to provide personal information and cooperate with government, etc.

thought the central government and the residence municipalities can be trusted in preventing the spread of COVID-19, which was about half of the percentage (41\%) trusting the health and medical bodies in Japan.

The above results indicate that more than $75 \%$ of respondents did not trust central and local governments in the early stages of the COVID-19 pandemic. This is also roughly consistent with the observations that $62 \%$ of respondents reported that the central government should be more accountable and $64 \%$ worried about future situations when there are more infections.

Perceptions about the effects and impacts of governmental policies/measures. Concerning the statement "the government's current outbreak control measures have a significant effect on reducing the risk of infection throughout Japan", $29 \%$ agreed but the same percentage $(29 \%)$ disagreed. The percentage of respondents who thought that countermeasures should be made more thoroughly were $56 \%$ for the central government and $48 \%$ for the municipalities where they lived. In line with such concerns, $65 \%$ of respondents did not agree to the statement "local governments where infection has not been confirmed do not need to take related measures at this moment".

Willingness to cooperate with government. Currently, the Japanese government has widely requested the population to exercise self-restraint. In the survey, $56 \%$ reported that they 
would like to exercise self-restraint. This percentage is contrary to the trust-related answers but consistent with perceptions about current governmental practices.

As already seen in some countries, tracing the infected persons' spatio-temporal behavioral trajectories is effective in detecting other infected persons and taking immediate measures. In the case of Japan, it is revealed that $37 \%$ thought that the infected person's activity trajectories should be published on an online map, conditional on proper privacy protection, while $35 \%$ answered that if they are infected, they do not have any psychological resistance to publishing their activity trajectories on an online map. However, these percentages are not high enough for the effective detection of COVID-19.

Such a low share of cooperation may be one of the critical reasons why the so-called Japan-specific cluster-focused countermeasures have not been as effective as expected. Why? This is because making cluster-focused countermeasures more effective requires the precise tracing of infected persons' spatiotemporal behavioral trajectories, which can only be captured by using personal GIS-enabled smartphones or similar smart devices.

\section{Quantifying the influencing sizes of factors to changes in life} To quantify how much the above-mentioned factors are influential to changes in life, a structural equation model (SEM) with five latent variables (Fig. 8) was estimated using the bootstrap method: [1] "changes in daily life" (the common dependent latent variable) (27 observed variables), [2] "reliability of information" (7 observed variables), [3] "risk perceptions" (11 observed variables), [4] "triggers of behavioral changes" (5 observed variables), [5] "attitudes" (25 observed variables) about various aspects of policymaking and personal matters. The latent variable [1] is related to all the other four latent variables; [2] explains all the other latent variables; [3] is used to explain [1], [4], and [5]; and [4] and [5] are further introduced to describe [1]. Figure 8 further shows standardized total effects.

The standardized total effects and their statistical significance indicate that the most influential factor to "changes in life" is the direct "triggers of behavioral changes" (0.402), followed by "risk perceptions". For "information reliability" and "attitudes", both direct and total effects are not significant on "changes in life". "Information reliability" and "risk perceptions" are confirmed to be significantly related to "triggers", respectively.
Looking at the standardized parameters of observed trigger variables, the latent variable "triggers" mostly represents recommendations from family (0.79) and from colleagues, acquaintances and friends (0.78). This means that effective interventions should be made by properly focusing on interactions of target persons with close members of their social networks. Similarly, the perceived risks, by respondents or by other persons, at residential province, city/town, and neighborhood are more influential to "changes in life" than other risks. Concerning "information reliability", the information from central and local governments are most influential to "changes in life".

Even though "attitudes" is not statistically significant in association with "changes in life", "information reliability" has a significant association with "attitudes". The more influential observed attitudes are: fair views about the infection by residence municipalities and the central government, trust in residence municipalities, readiness of management systems and measures of the central government, trust in the central government, enthusiasm of the central government, readiness of management systems and measures of residence municipalities, knowledge of the central government and residence municipalities, enthusiasm of residence municipalities, information disclosure by the central government and residence municipalities, and knowledge of medical and health institutes in Japan.

\section{Analyses for differentiated communications}

In practice, it is necessary to communicate with the public to elicit effective behavioral changes for slowing down the spread of COVID-19. However, different behavioral changes may take place depending on the different types of communications used. To confirm this, an analysis based on a data mining approach called "CHAID: Chi-square Automatic Interaction Detector" (Biggs et al., 1991) was carried out, by treating the following eight important behavioral changes as target variables and all the observed 48 variables of the above latent variables ("reliability of information", "risk perceptions", "triggers of behavioral changes", and "attitudes") as their predictors. The data mining results are summarized below (here, "other persons" refer to those people living/working near the respondents).

Telework or study at home increased: The most influential predictor is "behavioral changes were triggered by requests from workplace/school", followed by personally-perceived

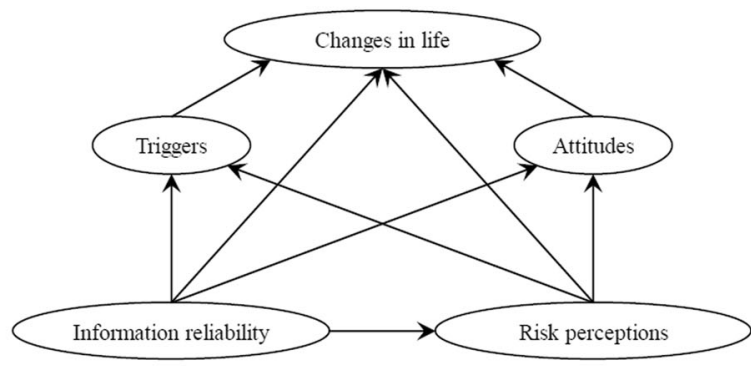

(Each cell: Left side with all observed variables $\mid$ Right side with selected variables)

\begin{tabular}{|l|r|c|c|c|}
\hline $\begin{array}{l}\text { Standardized total } \\
\text { effects }\end{array}$ & Information reliability & Risk perceptions & Attitudes & Triggers \\
\hline Risk perceptions & $0.038 \mid 0.010$ & - & - & - \\
\hline Attitudes & $0.445 \mid 0.432$ & $-0.031-0.018$ & - & - \\
\hline Triggers & $0.136 \mid 0.103$ & $0.319 \mid 0.315$ & - & - \\
\hline Changes in daily life & $0.052 \mid 0.053$ & $0.271 \mid 0.233$ & $-0.034 \mid-0.050$ & $0.402 \mid 0.358$ \\
\hline
\end{tabular}

Fig. 8 Relationships between changes in life and factors. It shows estimation results of a structural equation model with latent variables, where a causeeffect relationship structure and standardized total effects are included. 
increase in infection risks at often-visited places, other persons' perceived increase in infection risks over the whole country, and fair views about COVID-19 by residence municipalities, in that order. Other observed variables are not related to this behavioral change.

Daily trips decreased: The confirmed predictors affecting this behavioral change in descending order are: "triggered by selfunderstanding about infection situations", reliability of the information from medical and health institutes, personal perception about the dangerousness of COVID-19, other persons' perceptions about infection risks in residence prefectures, other persons' perceptions about infection risks over the whole country, enthusiasm of residence municipalities, and readiness of management systems and measures in residence municipalities.

Visiting crowded places was avoided as much as possible: The influential predictors associated with this behavioral change are: Willingness of keeping self-restraint until the lifting of the request by government, perception of the dangerousness of COVID-19, other persons' perceptions about infection risks over the whole country, "triggered by requests from governments", and reliability of the information from workplace/ school, in that order.

Domestic travel decreased: The revealed influential predictors are: "triggered by requests from governments", fair views by residence municipalities, other persons' perceptions about infection risks in residence cities/towns, perceived large effects of the current governmental measures, personally-perceived increase in infection risks in residence cities/towns, and willingness to information disclosure about personal infection and behavioral trajectories, in order.

Overseas travel decreased: The influential predictors in descending order are: other persons' perceptions about infection risks in residence cities/towns, "triggered by recommendations from colleagues, acquaintance and friends", worries about governmental responses against the widespread COVID-19, and information disclosure by the central government.

Tried to purchase as many masks as possible: This panic buying is mostly influential to other persons' perceptions about infection risks in residence neighborhoods, followed by accountability by residence municipalities, other persons' perceptions about infection risks in residence prefectures, and concerns about a short-term stagnation in the Japanese economy caused by current governmental measures. This means that this panic buying is more related to other persons' reactions, governmental accountability, and economic concerns.

Tried to purchase antiseptic solution as much as possible: Among all the 48 predictors, only two are found to affect this panic buying: concerns about a short-term stagnation in the Japanese economy caused by current governmental measures, and other persons' perceptions about infection risks in residence neighborhoods. This means that this panic buying is more influential to economic concerns and other persons' reactions.

Tried to encourage behavioral changes of other people surrounding respondents against the infection: Positive social interactions are useful to slow down the spread of COVID-19. It is found that "triggered by self-understanding about infection situations", concerns about a short-term stagnation in the Japanese economy caused by current governmental measures, perceptions by other persons' perceptions about infection risks in residence cities/towns, personally-perceived increase in infection risks in residence neighborhoods, and "triggered by recommendations from colleagues, acquaintance and friends" affects this behavioral change, in that order. Interestingly, this social interaction related behavioral change is associated with the influences from "other persons" and "colleagues, acquaintance and friends".

All the above results suggest that different behavioral changes need to be addressed through different types of interventions via effective risk communications. Without careful design of differentiated communications to different stakeholders (governments, households, individuals, workplaces, schools, and organizations and so on), it is difficult to expect behavioral changes to be beneficial for the prevention of virus transmission.

\section{Discussions and conclusions}

Based on a nation-wide questionnaire survey, this study has revealed the various changes in life in the early stages (end of March 2020) of the COVID-19 pandemic in Japan, as well as the potential factors behind the observed changes. This may be the first attempt in the literature, at least in countries like Japan where confirmed infection cases were still relatively low at the time of survey, to capture joint changes of various behaviors and factors affecting the changes, as well as to clarify the influencing sizes of factors behind behavioral changes. Important findings are summarized below.

- The February 28 announcement of school closures by the central government was the biggest trigger to bring about behavioral changes against the spread of COVID-19 in Japan. However, the announcement of the COVID-19 pandemic by $\mathrm{WHO}$ and requests of behavioral changes (including selfrestraint requests) to the public by the novel coronavirus task force of the central government could not further encourage behavioral changes toward flattening the curve of COVID-19 by the end of March.

- Even though the Japanese government and local municipalities made various efforts, many respondents showed strong concerns about information disclosure and reliability, abilities of decision makers, insufficient social communication, accountability, and effects of measures.

- To slow down the spread of COVID-19, strong and effective cooperation from the public is essential. Unfortunately, even in March, the share of self-restraint was not sufficiently high. Undoubtedly, this is one of the important reasons for the spread of the pandemic. However, such a low share of selfrestraint may be largely due to weak relationships between the general public and government, i.e., there is not enough mutual trust.

- Insufficient mutual trust may be due to not only poor communications but also weak intensity of policies and measures (e.g., effective detection of infected cases, protection measures at various places, including public transport vehicles and facilities), as well as slow learning about successes and failures from other countries.

- SEM analyses reveal that recommendations from respondents' close social network members (family, colleagues, acquaintance and friends) are most useful to bring about expected changes in life, among the factors of "reliability of information", "risk perceptions", and "attitudes", as well as "triggers of behavioral changes". To make these recommendations work well, the reliability of the COVID-19 information from central and local governments is the key. It is also essential to facilitate people's ability to recognize infection risks because it is linked to direct triggers of behavioral change. Thus, being consistent with aggregate analyses, the modeling results also confirm that lack of effective communications may be a key factor causing the spread of COVID-19 in Japan. 
- Data mining results suggest the importance of differentiated communications to encourage different types of behavioral changes.

Lower levels of behavioral changes may be due to the lack of a sense of crisis and people's lack of awareness or concern about their contribution to society. ${ }^{10}$ Unclear requests for self-restraint, poor role specifications of central and local governments in COVID-19 policies, and the resulting policy turmoil, discourage people from following governmental requests/recommendations. This research suggests that it is important to figure out effective differentiated communication methods for informing the public to make cooperative behavioral changes. To avoid/mitigate the infection risk, physical distancing has to be better practiced. Therefore, it is necessary for people to re-think what kinds of essential needs in life [L] have to be met and accordingly to redesign their daily life schedules. Based on the re-designed schedules, people needs to further carefully think about what kinds of out-of-home or out-of-office activities [A] have to be performed, at what kinds of places with sufficient space [S] and proper duration of time and at the proper timing [TING] (for example, to perform activities as quickly as possible and to shift departure timing). In other words, a Life-oriented Activity-Space-Timing (LASTING) approach is required for people to survive COVID19. Such a LASTING approach is crucial to enhance the effects of massive public involvement in mitigating the spread of COVID-19.

One question which remains is, what kinds of higher-order needs in life can be temporarily ignored or postponed during the fight against COVID-19, and for how long can people tolerate this? Obviously, the answers will vary, depending on personal situations. To avoid being infected and unconsciously transmitting the virus to other people, it is necessary for people to carefully choose their activities in terms of types (derived from needs in life), locations and time (for how long and when). If activities which are crucial for meeting fundamental needs in life are cancelled by governmental requests, it becomes important for policymakers to clarify how they will compensate for the economic losses due to the activity cancellation. To ensure those needed activities are performed at appropriate places with sufficient spaces and at the proper time, effective regulations and other governmental support may be further required. More relevant research efforts should be made in the future.

The findings from this study also suggest that it is necessary to rebuild those virus infection prediction models which ignore links between behavioral changes and the spread of viruses. Without incorporating the influences of behavioral changes on the spread of COVID-19, as well as other public health threats, it will be difficult to convince people to follow governmental requests for behavioral changes.

\section{Data availability}

Data are available from the author on reasonable request. It is not made accessible publicly because of the agreement with the survey respondents.

Received: 18 May 2020; Accepted: 11 January 2021; Published online: 03 February 2021

\section{Notes}

1 This data comes from https://coronavirus.jhu.edu/map.html.

2 The total number of registered survey panels were about 4.65 million, as of March 2020. The 1052 respondents were randomly recruited from these 4.65 million panels.
3 The central government of Japan declared a state of emergency for seven prefectures of Tokyo, Saitama, Chiba, Kanazawa, Osaka, Hyogo, and Fukuoka on April 7, which was about 40 days later than the declaration in Hokkaido. Following the declaration in Hokkaido, infection cases gradually decreased and as a result, on March 19, the Hokkaido governor cancelled the declaration. Unfortunately, in early April, the number of cases of infections in Hokkaido increased dramatically (https://www.asahi. com/articles/ASN565VQTN54IIPE012.html).

4 For example, the following two surveys are very impressive: (1) The lifestyle survey by Statista.com (https://www.statista.com/statistics/1105960/changes-to-the-generallifestyle-due-to-covid-19-in-selected-countries/) [Accessed on May 7, 2020];(2). COVID-19 Community Mobility Reports-Google (https://www.google.com/covid19/ mobility/) [Accessed on May 7, 2020]

5 https://www.jaero.or.jp/data/01jigyou/survey_pickup.html (in Japanese) [Accessed March 3, 2020].

6 Calculated using an exchange rate of $1 \mathrm{JPY}=0.009605$ USD for March 30, 2020 [www.exchange-rates.org].

7 https://wttc.org/News-Article/Latest-research-from-WTTC-shows-a-50-percentageincrease-in-jobs-at-risk-in-Travel-and-Tourism [Accessed on May 7, 2020].

8 https://newswitch.jp/p/21625 (in Japanese) [Accessed on May 7, 2020].

9 https://newswitch.jp/p/21906 (in Japanese) [Accessed on May 7, 2020].

$10 \mathrm{https} / / /$ www.newsweekjapan.jp/tokyoeye/2020/05/post-21.php (in Japanese) [Accessed on May 10, 2020].

\section{References}

Bavel JJV, Baicker K, Boggio PS et al. (2020) Using social and behavioural science to support COVID-19 pandemic response. Nat Hum Behav 4:460-471

Belli RF (1998) The structure of autobiographical memory and the event history calendar: potential improvements in the quality of retrospective reports in surveys. Memory 6(4):383-406

Biggs D, De Ville B, Suen E (1991) A method of choosing multiway partitions for classification and decision trees. J Appl Stat 18:49-62

Caputo R, Gelmetti C, Ermacora E, Gianni E, Silvestri A (1992) Gianotti-Crosti syndrome: a retrospective analysis of 308 cases. J Am Acad Dermatol 26 (2):207-210

Cowling BJ, Ali ST, Ng TWY, Tsang TK, Li JCM, Fong MW, Liao Q, Kwan MYW, Lee SL, Chiu SS, Wu JT, Wu P, Leung GM (2020) Impact assessment of nonpharmaceutical interventions against Coronavirus Disease 2019 and Influenza in Hong Kong: an observational study. Lancet Public Health 5(5): e279-e288

Pasquini-Descomps H, Brender N, Maradan D (2017) Value for money in H1N1 Influenza: a systematic review of the cost-effectiveness of pandemic interventions. Value Health 20(6):819-827

Piltch-Loeb R, Merdjanoff AA, Bhanja A, Abramson DM (2019) Support for vector control strategies in the United States during the Zika outbreak in 2016: the role of risk perception, knowledge, and confidence in government. Prevent Med 119:52-57

Schröder M (2011) Retrospective Data Collection in the Survey of Health, Ageing and Retirement in Europe. SHARELIFE Methodology. MEA, Mannheim. http://www.share-project.org/uploads/tx_sharepublications/FRBMethodology_feb2011_color-1.pdf (Accessed on 30 Nov 2020)

Sell TK, Boddie C, McGinty EE, Pollack K, Smith KC, Burke TA, Rutkow L (2016) News media coverage of U.S. Ebola policies: implications for communication during future infectious disease threats. Prevent Med 93:115-120

Skrip LA, Bedson J, Abramowitz S, Jalloh MB, Bah S, Jalloh MF, Langle-Chimal OD, Cheney N, Hebert-Dufresne L, Althouse BM (2020) Unmet needs and behaviour during the Ebola response in Sierra Leone: a retrospective, Mixedmethods Analysis of Community Feedback from the Social Mobilization Action Consortium. Lancet Planet Health 4:e74-e85

Soper GA (1919) The lessons of the pandemic. Science 49:501-506

Thigpen C (2019) Measurement validity of retrospective survey questions of bicycling use, attitude, and skill. Transport Res Part F 60:453-461

West R, Michie S, Rubin GJ, Amlôt R (2020) Applying principles of behaviour change to reduce SARS-CoV-2 transmission. Nat Hum Behav 4:451-459

Yang Y, Peng F, Wang R, Yang M, Guan K, Jiang T, Xu G, Sun J, Chang C (2020) The deadly Coronaviruses: the 2003 SARS Pandemic and the 2020 Novel Coronavirus Epidemic in China. J Autoimmun 109:102434. https://doi.org/ 10.1016/j.jaut.2020.102434

Zhang J (2014) Revisiting the residential self-selection issues: a life-oriented approach. J Land Use Transport 7(3):29-45

Zhang J (2017) Life-oriented behavioral research for urban policy. Springer, Tokyo

\section{Funding}

This study was funded by the author's university, but nobody in the university was involved in this study. 


\section{Competing interests}

The author declares no competing interests.

\section{Additional information}

Correspondence and requests for materials should be addressed to J.Z.

Reprints and permission information is available at http://www.nature.com/reprints

Publisher's note Springer Nature remains neutral with regard to jurisdictional claims in published maps and institutional affiliations. (c) (i) Open Access This article is licensed under a Creative Commons Attribution 4.0 International License, which permits use, sharing, adaptation, distribution and reproduction in any medium or format, as long as you give appropriate credit to the original author(s) and the source, provide a link to the Creative Commons license, and indicate if changes were made. The images or other third party material in this article are included in the article's Creative Commons license, unless indicated otherwise in a credit line to the material. If material is not included in the article's Creative Commons license and your intended use is not permitted by statutory regulation or exceeds the permitted use, you will need to obtain permission directly from the copyright holder. To view a copy of this license, visit http://creativecommons.org/ licenses/by/4.0/

(C) The Author(s) 2021 